\title{
Efficacy and safety of baricitinib for active rheumatoid arthritis in patients with an inadequate response to conventional synthetic or biological disease-modifying anti-rheumatic drugs: A meta-analysis of randomized controlled trials
}

\author{
ZHI-PENG WU ${ }^{1 *}$, PEI ZHANG ${ }^{2 *}$, JIAN-ZHONG BAI $^{2}$, YUAN LIANG $^{3}$, JIN-SHAN HE ${ }^{3}$ and JING-CHENG WANG $^{1-3}$ \\ ${ }^{1}$ Department of Orthopedics, The Second Xiangya Hospital, Central South University, Changsha, Hunan 410011; \\ ${ }^{2}$ Department of Orthopedics, Dalian Medical University, Dalian, Liaoning 116044; ${ }^{3}$ Department of Orthopedics, Clinical \\ Medical College of Yangzhou University, Subei People's Hospital of Jiangsu Province, Yangzhou, Jiangsu 225001, P.R. China
}

Received October 22, 2017; Accepted June 1, 2018

DOI: $10.3892 /$ etm.2018.6495

\begin{abstract}
The purpose of the present meta-analysis was to assess the efficacy and safety of baricitinib for active rheumatoid arthritis (RA) in patients with an inadequate response or intolerance to conventional synthetic or biological disease-modifying anti-rheumatic drugs (DMARDs). A total of 7 randomized controlled trials (RCTs) were included. The primary effective outcome was the RA improvement to reach an American College of Rheumatology 20\% (ACR20) response rate. The safety outcomes were composed of clinical laboratory parameters. All patients included received $4 \mathrm{mg}$ baricitinib once daily to treat RA for 12 or 24 weeks. The ACR20 response rate in the baricitinib group was significantly higher compared with that in the control group at 12 weeks [relative risk (RR), 1.77; 95\% confidence interval (CI), 1.62-1.94;
\end{abstract}

Correspondence to: Professor Jing-Cheng Wang or Dr Jin-Shan He, Department of Orthopedics, Clinical Medical College of Yangzhou University, Subei People's Hospital of Jiangsu Province, 98 Nantong West Road, Yangzhou, Jiangsu 225001, P.R. China

E-mail: wangjcyangzhou@163.com

E-mail: yzhjs163@163.com

*Contributed equally

Abbreviations: RA, rheumatoid arthritis; DMARD, disease-modifying anti-rheumatic drug; RCT, randomized controlled trial; ACR20, American College of Rheumatology 20\% response rate; HAQ-DI, Health Assessment Questionnaire-Disability Index score; SDAI, Simplified Disease Activity Index score; PtGA, Patient's Global Assessment of Disease Activity; AE, adverse event; ALT, alanine transaminase; LDL, low-density lipoprotein; HDL, high-density lipoprotein; RR, relative risk; MD, mean difference; SMD, standardized mean difference; CI, confidence interval

Key words: baricitinib, Janus kinase inhibitor, efficacy, safety, rheumatoid arthritis, meta-analysis
$\mathrm{P}<0.00001]$ and 24 weeks (RR, 1.76; 95\% CI, 1.48-2.10; $\mathrm{P}<0.00001)$. Similarly, other effective outcome measures also exhibited significant improvements in the baricitinib group compared with those in the placebo group. Regarding the safety outcomes, no significant difference in adverse events (AEs) was identified at 12 weeks $(\mathrm{P}=0.14)$, but AEs were significantly higher in the baricitinib group compared with those in the control group at 24 weeks $(\mathrm{P}=0.03)$. Most laboratory values were significantly different between the baricitinib and placebo groups; however, the clinical significance of these changes remains to be determined. In summary, the present meta-analysis demonstrated that $4 \mathrm{mg}$ baricitinib once daily was beneficial in patients with active RA with an inadequate response or intolerance to conventional synthetic or biological DMARDs. More high-quality RCTs are required to determine the sustained efficacy and the safety of baricitinib.

\section{Introduction}

Rheumatoid arthritis (RA) is a systemic and autoimmune disease, which is caused by massive autoimmune reactive cell populations and cytokines $(1,2)$. The therapeutic goals are to achieve clinical remission of disease activity and reduce long-term joint destruction (3). It has been reported that the combined use of biological and conventional synthetic disease-modifying anti-rheumatic drugs (DMARDs) was more effective than monotherapy in the treatment of RA (4). However, an increasing number of studies have indicated that patients failed to respond or tolerate conventional synthetic or biological DMARDs following decades of treatment. Thus, targeted synthetic DMARDs (4), oral low-molecular-weight drugs, which target kinase proteins, including Janus kinases (JAKs), have been developed to treat RA.

The JAK family, including JAK1, JAK2, JAK3 and tyrosine kinase 2 (Tyk2), has critical roles in certain signaling pathways through activating cytokine-induced phosphorylation of signal transducer and activators of transcription (STAT), which is then directly transported to the nucleus to regulate the transcription of its target genes $(5,6)$. According to Fridman et al $(7)$ 
and Shi et al (8), baricitinib is an novel, oral low-molecularweight JAK inhibitor with good selectivity for JAK1 [concentration leading to $50 \%$ inhibition $\left.\left(\mathrm{IC}_{50}\right)=5.7 \mathrm{nM}\right]$ and JAK2 $\left(\mathrm{IC}_{50}=5.9 \mathrm{nM}\right)$, and less selectivity for JAK3 $\left(\mathrm{IC}_{50}>400 \mathrm{nM}\right)$ or Tyk $2\left(\mathrm{IC}_{50}=53 \mathrm{nM}\right)$, and the kidneys are considered to be the principal organ to eliminate baricitinib. Shi et al (8), Kubo et al (9) and Emery et al (10) reported that baricitinib inhibits the phosphorylation of STATs induced by various cytokines in the whole blood, and results in a transient change in neutrophil and lymphocyte counts. A previous meta-analysis suggested that the use of the JAK inhibitor tofacitinib is associated with manageable safety and increased clinical efficacy in the short-term compared with placebo (11). Tofacitinib has similar inhibitory activity on JAK1 and JAK3, but less activity against JAK2 (12). To date, the clinical efficacy of JAK inhibitors (preferential JAK1 and JAK2 inhibitors) has remained to be accurately defined by the results of independent clinical trials. The objective of the present meta-analysis was to determine the clinical efficacy and safety of baricitinib administered at the dosage of $4 \mathrm{mg}$ once daily for patients with an inadequate response to conventional synthetic or biological DMARDs.

\section{Materials and methods}

Inclusion and exclusion criteria. Randomized controlled trials (RCTs) were eligible if they met the following inclusion criteria: i) Patients aged $>18$ years with an inadequate response or intolerance to conventional synthetic or biological DMARDs; ii) the studies compared the use of baricitinib with that of a placebo in the treatment of RA; and iii) the studies provided data for evaluating the clinical efficacy and safety of baricitinib. The exclusion criteria were as follows: i) The studies included duplicate and incomplete data; and ii) the entries retrieved were for unsuitable publications, including conference abstracts or review articles.

Information sources and search strategy. The present meta-analysis adhered to the guidelines of the Preferred Reporting Items for Systematic Reviews and Meta-Analyses statement (13). The data was extracted independently by two investigators (ZPW and PZ) and was rechecked following the first extraction. Two investigators (JSH and JCW) discussed disagreements arising from the extraction until a consensus was reached. Electronic databases, including Medline (https://www.nlm.nih.gov/), Embase (https://www.elsevier. com/), Science Direct (https://www.sciencedirect.com/), Web of Science (http://login.webofknowledge.com/) and the Cochrane library (http://www.cochranelibrary.com/), were searched to retrieve relevant studies published until July 3, 2017. The publications were not restricted with regard to publication status or language. The following data were extracted from the RCTs: Name of first author, year of publication, country, duration of follow-up, primary outcomes for efficacy and safety, and mean and standard deviation of changes, including laboratory outcomes regarding hemoglobin, alanine transaminase (ALT), neutrophil, lymphocyte, creatinine, low density lipoprotein (LDL) and high density lipoprotein (HDL) from baseline. The data, including the American College of Rheumatology 20\% response (ACR20) (14) and Simplified Disease Activity Index (SDAI) $\leq 3.3$ (15), were extracted from the published figures using the 'Get Data Graph Digitizer' software (v2.24; http://getdata-graph-digitizer.com/). The risk of bias of the eligible studies was assessed by the Cochrane collaboration's tool (http://community.cochrane. org/help/tools-and-software/revman-5/).

Outcome measures. Efficacy measures were as follows: i) The proportion of patients achieving an ACR20; ii) the SDAI $\leq 3.3$; iii) patient-reported outcomes (PROs), including the Patient's Global Assessment of Disease Activity (PtGA) (16) and Scores on the Health Assessment Questionnaire-Disability Index (HAQ-DI) (17). The safety outcomes included the following: i) Adverse events (AEs), ii) discontinuation due to AEs, iii) infections, and iv) serious infections, including pneumonia and cellulitis. Serious infections were defined as those requiring hospitalization and/or parenteral antibiotics or otherwise meeting serious adverse events, including fatal or life-threatening, requiring hospitalization or extension of existing hospitalization, resulting in persistent or significant disability/incapacity or congenital abnormality/birth defect or considered to be an important medical event. All clinical laboratory outcomes are reported as the least-squares mean change from baseline, which included the following: i) Hemoglobin; ii) neutrophils; iii) lymphocytes; iv) ALT; v) creatinine; vi) $\mathrm{HDL}$; and vii) LDL.

Quality assessment. Two investigators (ZPW and PZ) independently assessed the quality of the RCTs according to the method in the Cochrane Reviewer's Handbook 5.1.0 (The Cochrane Collaboration, London, UK) (18). The risk of bias of individual studies was assessed according to the Cochrane risk assessment scale and included the following: Details of the methods of random sequence generation, allocation concealment, blinding, incomplete outcome data, selective outcome reporting and other sources of bias. Any disagreements were resolved by a third reviewer (JSH).

Statistical and sensitivity analysis. Statistical heterogeneity of data was evaluated by using Cochran's Q statistics. If the $\mathrm{Q}$ statistics indicated significant heterogeneity among the studies $(\mathrm{P}<0.10)$, a random-effects model was employed for the meta-analysis, and otherwise, a fixed-effects model was used. The results for continuous data (HAQ-DI, PtGA, neutrophils, lymphocytes, creatinine, hemoglobin LDL and HDL) are presented as the mean difference (MD) with 95\% confidence interval (CI). For ALT, the standardized mean difference (SMD) was calculated using the inverse variance method. For dichotomous data, the risk ratio (RR) was calculated using the Mantel-Haenszel method. The mean difference and standardized mean difference were considered statistically significant at the $\mathrm{P}<0.05$ level. Data analysis was performed by using Review Manager 5.3 (The Cochrane Collaboration). Sensitivity analysis was performed to assess the results through exclusion of one eligible study at a time.

\section{Results}

Study selection. A total of 7 RCTs compared the use of baricitinib with that of a placebo in patients with active RA with an inadequate response or intolerance to conventional synthetic or biological DMARDs (Fig. 1). The study by Fleischmann et al (19) 


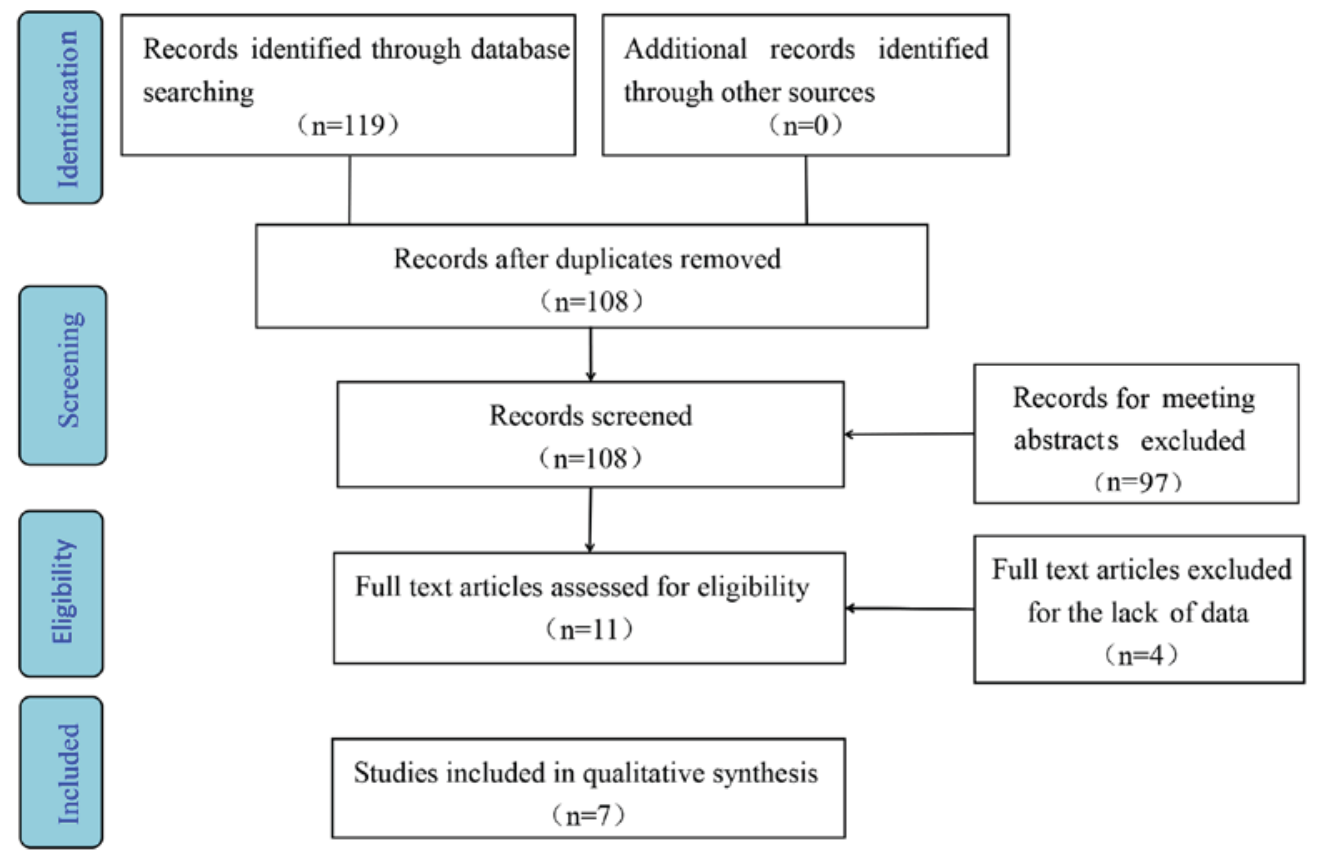

Figure 1. Flow chart of the study selection procedure.

was ignored due to the combined use of baricitinib and methotrexate (MTX). A total of 4 studies were eliminated due to the lack of available data for analysis (20-23). Finally, 7 RCTs were selected, including 2 phase-II $(24,25)$ trials and 5 phase-III trials (3,26-29). The dosage of baricitinib ranged from 1 to $8 \mathrm{mg}$ $(1,2,4$ and $8 \mathrm{mg})$ once daily. A total of 4,173 patients were included in this meta-analysis. 1,371 patients were included in the $4 \mathrm{mg}$ baricitinib group and 1,443 patients were included in placebo group. The mean age of the patients ranged from 51.7 to 57.5 years in the $4 \mathrm{mg}$ group and 49 to 56 years in the placebo group. A summary of the RCTs is presented in Table I.

Risk-of-bias assessment. The results of the Cochrane risk of bias assessment are presented in Fig. 2. None of the studies included described the method of allocation concealment. The study by Keystone et al (25) had a high risk of bias regarding the blinding of participants and personnel and an unclear risk of bias regarding the blinding during the outcome assessment. Two studies presented an unclear risk of attrition bias $(26,29)$. Tanaka et al (28) did not describe the method of random sequence generation. Sensitivity analysis was performed by excluding one study at a time and in each case all of the results remained stable. The efficacy and safety of baricitinib was assessed at the dosage of $4 \mathrm{mg}$, as this dose was considered to be most effective in all RCTs included. Furthermore, the eligible studies did not provide sufficient data to evaluate the efficacy and safety of baricitinib at any of the other doses.

Efficacy of baricitinib (4 $\mathrm{mg}$ once daily) at 12 and 24 weeks ACR 20 response rate. The ACR 20 response rate at 12 weeks was extracted from 5 studies $(3,24,25,27,28)$, and a low heterogeneity was observed $\left(\mathrm{I}^{2}=0 \%\right)$. The efficacy outcomes are presented in Table II. At 12 weeks, the ACR20 response rate in the baricitinib group was significantly higher than that in the placebo group [RR, 1.77; 95\% CI, 1.62-1.94; $\mathrm{P}<0.00001$; Fig. 3A). At 24 weeks, the ACR20 response rate in the baricitinib-4 mg group, which was extracted from 3 studies $(3,24,27)$, was significantly higher than that in the placebo group (RR, 1.76; 95\% CI, 1.48-2.10; $\mathrm{P}<0.00001$; Fig. 3B). A higher heterogeneity was seen when compared with that at 12 weeks $\left(I^{2}=62 \%\right)$.

$S D A I \leq 3.3$. The ratio of patients who achieved SDAI $\leq 3.3$ at 12 weeks was reported in 4 studies $(3,24,25,27)$ and a low heterogeneity was observed $\left(\mathrm{I}^{2}=20 \%\right)$. A statistically significant improvement was observed in the baricitinib once daily groups compared with that in the placebo group (RR, 4.57; 95\% CI, 2.78-7.52; P<0.00001; Fig. 4A). Patients receiving baricitinib (3 studies) $(3,24,27)$ had a significant improvement compared with those receiving placebo at 24 weeks (RR, 4.58; 95\% CI, 3.08-6.82; P<0.00001; Fig. 4B).

$H A Q-D I$ and PtGA. All parameters exhibited low heterogeneity and a fixed effect model was applied. The HAQ-DI and PtGA were extracted from 2 studies $(26,29)$. Baricitinib was associated with a significant reduction in the HAQ-DI score compared with that in the placebo group at 12 weeks [MD, -0.22 ; 95\% CI, -(0.30-0.14); $\mathrm{P}<0.00001](26,29)$ and 24 weeks [MD, -0.26; 95\% CI, -(0.34-0.17) (26,29); P<0.00001; Table II]. While the other studies did not provide sufficient data for analysis, the results of all eligible studies confirmed a statistically significant improvement in the HAQ-DI in the baricitinib compared with that in the placebo group in the short-term (24 weeks). Similarity, patients receiving baricitinib had lower PtGA scores compared with those in the group receiving placebo at 12 weeks (MD, -10.99; 95\% CI, -(14.55-7.44); $\mathrm{P}<0.00001](26,29)$ and 24 weeks [MD, -12.4; 95\% CI, -(16.02-8.77); P<0.00001; Table II) $(26,29)$.

Safety of baricitinib (4 mg once daily) at 12 and 24 weeks. The safety outcomes are presented in Table III. A total of 4 studies reported on AEs at 12 weeks $(3,25,27,28)$, and no significant 


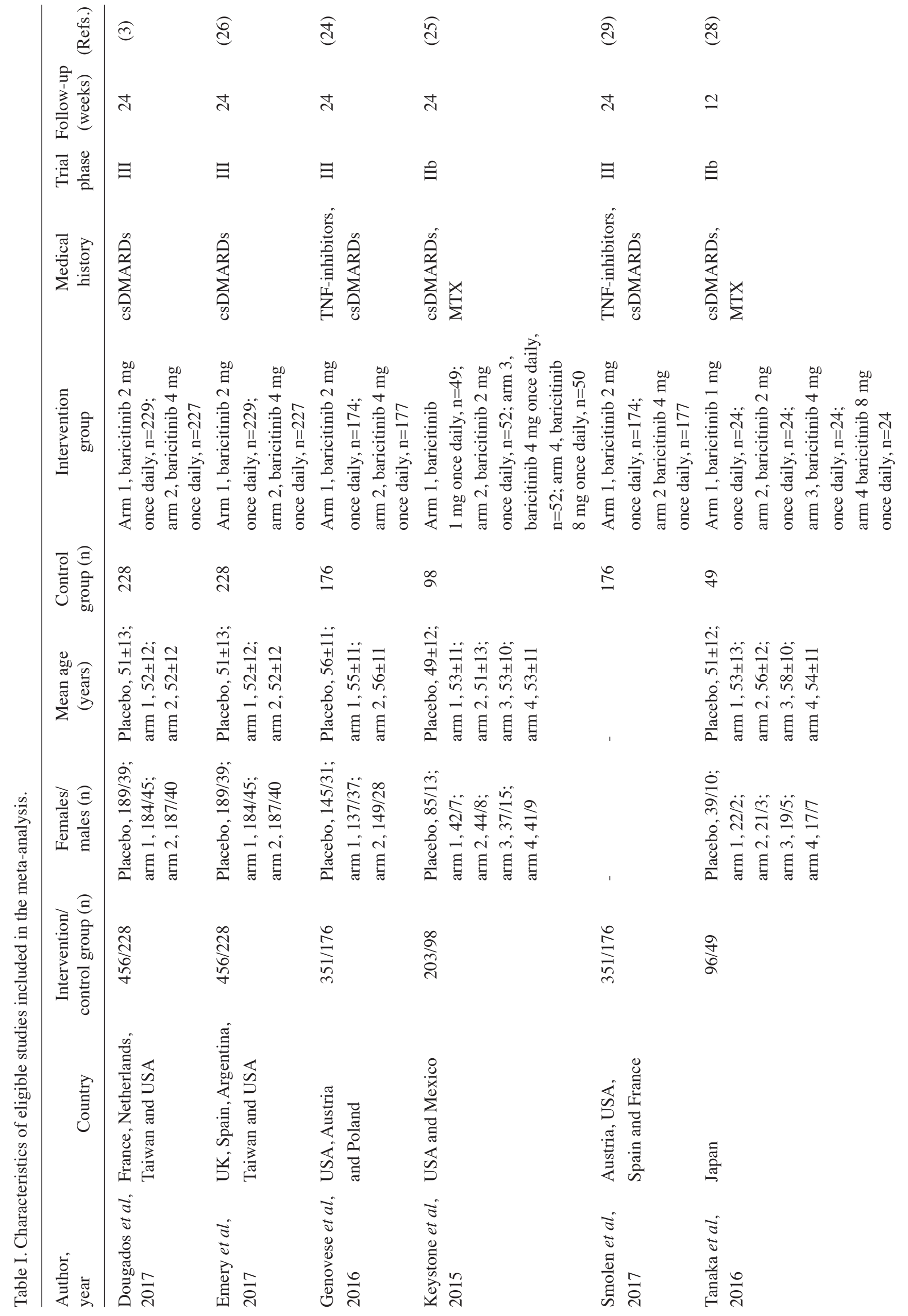



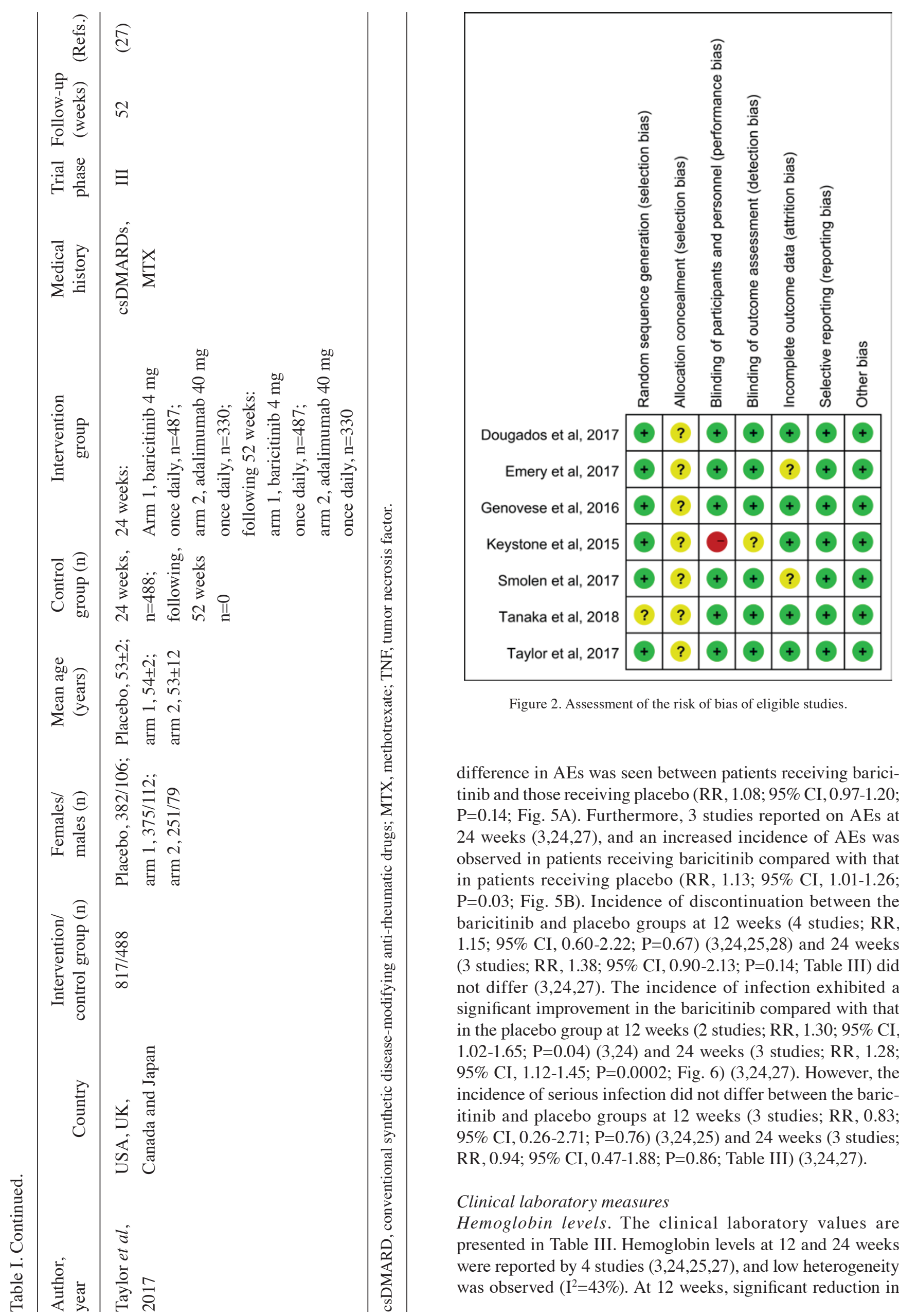

Figure 2. Assessment of the risk of bias of eligible studies.

difference in AEs was seen between patients receiving baricitinib and those receiving placebo (RR, 1.08; 95\% CI, 0.97-1.20; $\mathrm{P}=0.14$; Fig. 5A). Furthermore, 3 studies reported on AEs at 24 weeks $(3,24,27)$, and an increased incidence of AEs was observed in patients receiving baricitinib compared with that in patients receiving placebo (RR, 1.13; 95\% CI, 1.01-1.26; $\mathrm{P}=0.03$; Fig. 5B). Incidence of discontinuation between the baricitinib and placebo groups at 12 weeks (4 studies; RR, $1.15 ; 95 \% \mathrm{CI}, 0.60-2.22 ; \mathrm{P}=0.67)(3,24,25,28)$ and 24 weeks (3 studies; RR, 1.38; 95\% CI, 0.90-2.13; P=0.14; Table III) did not differ $(3,24,27)$. The incidence of infection exhibited a significant improvement in the baricitinib compared with that in the placebo group at 12 weeks (2 studies; RR, 1.30; 95\% CI, 1.02-1.65; $\mathrm{P}=0.04)(3,24)$ and 24 weeks (3 studies; RR, 1.28; $95 \%$ CI, 1.12-1.45; P=0.0002; Fig. 6) $(3,24,27)$. However, the incidence of serious infection did not differ between the baricitinib and placebo groups at 12 weeks (3 studies; RR, 0.83; 95\% CI, 0.26-2.71; $\mathrm{P}=0.76)(3,24,25)$ and 24 weeks (3 studies; RR, 0.94; 95\% CI, 0.47-1.88; P=0.86; Table III) $(3,24,27)$.

\section{Clinical laboratory measures}

Hemoglobin levels. The clinical laboratory values are presented in Table III. Hemoglobin levels at 12 and 24 weeks were reported by 4 studies $(3,24,25,27)$, and low heterogeneity was observed $\left(\mathrm{I}^{2}=43 \%\right)$. At 12 weeks, significant reduction in 
Table II. Efficacy of baricitinib in patients with active rheumatoid arthritis.

A, Baricitinib, $4 \mathrm{mg}, 12$ weeks

\begin{tabular}{|c|c|c|c|c|c|c|c|}
\hline \multirow[b]{2}{*}{ Studies (n) } & \multirow[b]{2}{*}{ Outcome } & \multicolumn{3}{|c|}{ Meta-analysis } & \multicolumn{3}{|c|}{ Test of heterogeneity } \\
\hline & & $\mathrm{RR}$ & $95 \%$ CI & P-value & Model & P-value & $\mathrm{I}^{2}(\%)$ \\
\hline 2 & HAQ-DI & $-0.22^{\mathrm{a}}$ & -0.30 to -0.14 & $<0.00001$ & $\mathrm{~F}$ & 0.63 & 0 \\
\hline 2 & PtGA & $-10.99^{a}$ & -14.55 to -7.44 & $<0.00001$ & $\mathrm{~F}$ & 0.17 & 47 \\
\hline
\end{tabular}

B, Baricitinib, $4 \mathrm{mg}, 24$ weeks

\begin{tabular}{|c|c|c|c|c|c|c|c|}
\hline \multirow[b]{2}{*}{ Studies (n) } & \multirow[b]{2}{*}{ Outcome } & \multicolumn{3}{|c|}{ Meta-analysis } & \multicolumn{3}{|c|}{ Test of heterogeneity } \\
\hline & & RR & $95 \% \mathrm{CI}$ & P-value & Model & P-value & $\mathrm{I}^{2}(\%)$ \\
\hline 2 & HAQ-DI & $-0.26^{\mathrm{a}}$ & -0.34 to -0.17 & $<0.00001$ & $\mathrm{~F}$ & 0.65 & 0 \\
\hline 2 & PtGA & $-12.4^{\mathrm{a}}$ & -16.02 to -8.77 & $<0.00001$ & $\mathrm{~F}$ & 0.14 & 55 \\
\hline
\end{tabular}

${ }^{a}$ Mean difference. ACR20, American College of Rheumatology 20\% response rate; HAQ-DI, Health Assessment; HAQ-DI, Questionnaire-Disability Index score; SDAI, Simplified Disease Activity Index score; PtGA, Patient's Global Assessment of Disease Activity; $\mathrm{RR}$, relative risk; F, fixed-effects model; CI, confidence interval; $\mathrm{I}^{2}$, heterogeneity.

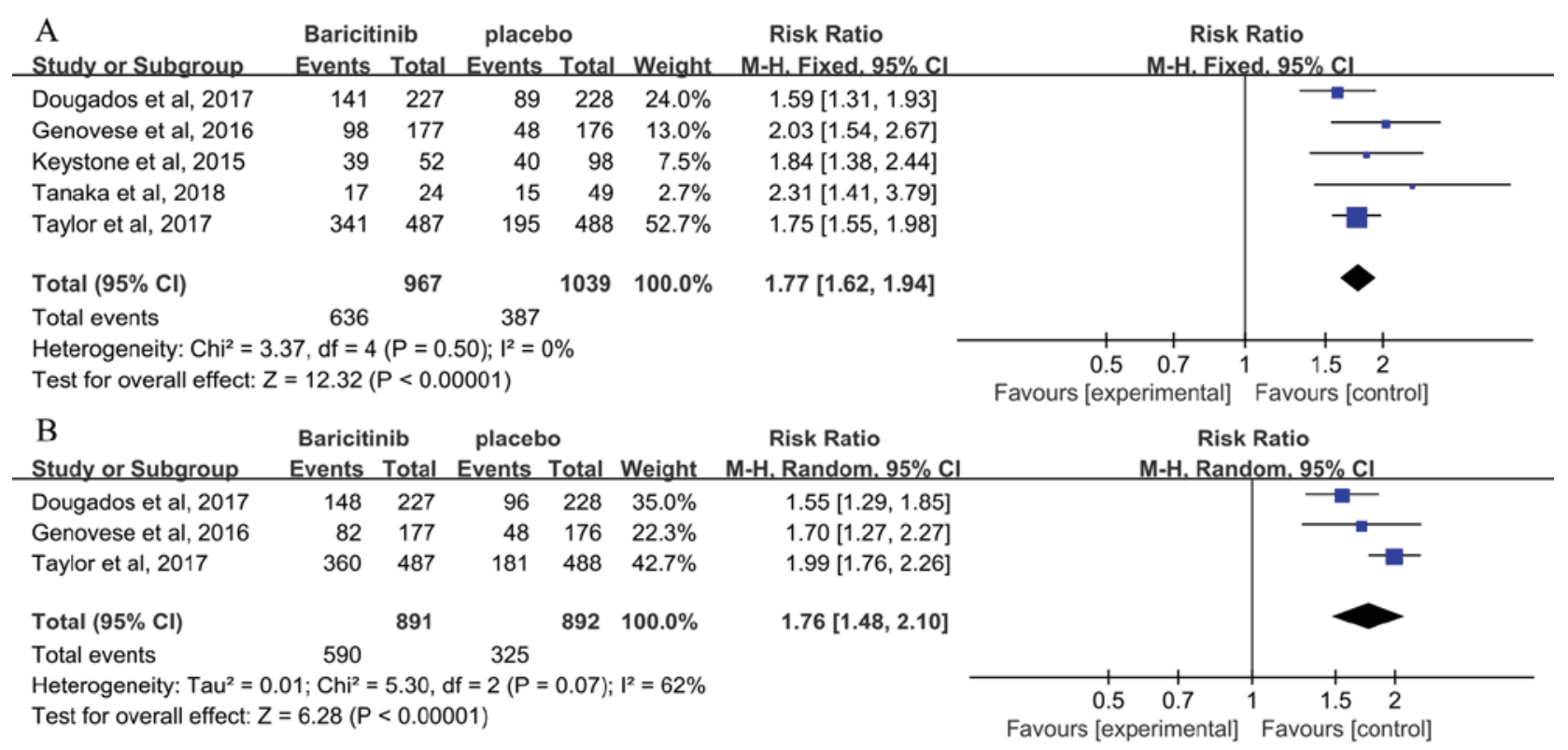

Figure 3. Forest plot diagram indicating the efficacy of baricitinib at the dose of $4 \mathrm{mg}$ once daily according to the American College of Rheumatology $20 \%$ response rate in patients with rheumatoid arthritis at (A) 12 and (B) 24 weeks. CI, confidence interval; df, degrees of freedom; M-H, Mantel-Haentzel. Risk ratio is presented as blue squares, with the horizontal line indicating the confidence interval. Combined results for all studies are presented as a black diamonds.

hemoglobin levels was determined in the baricitinib compared with that in the placebo group (MD, -0.18 ; 95\% CI, -(0.28-0.08); $\mathrm{P}=0.0003$; Fig. 7A) $(3,24,25)$. However, at 24 weeks, no difference in hemoglobin levels was observed between patients receiving baricitinib and those receiving placebo $(3,24,27)$ (MD, -0.10; 95\% CI, -0.27-0.07; P=0.23; Fig. 7B).

Neutrophil, lymphocyte, ALT and creatinine levels. Baricitinib treatment was associated with a significantly lower neutrophil count than placebo treatment at 12 weeks [ 3 studies; MD, -0.64; 95\% CI, -(0.87-0.41); P<0.00001] $(3,24,25)$ and 24 weeks
[3 studies; MD, -0.67; 95\% CI, -(0.87-0.47); $\mathrm{P}<0.00001$; Table III] $(3,24,27)$. No significant difference was observed in lymphocyte counts between patients receiving baricitinib and those receiving placebo at 12 weeks (3 studies; MD, 0.07; 95\% CI, $-0.08-0.21 ; \mathrm{P}=0.35)(3,24,25)$ and 24 weeks (3 studies; MD, -0.02; 95\% CI, -0.08-0.05; P=0.61; Table III) $(3,24,27)$. Patients receiving baricitinib had significantly higher ALT levels compared with those receiving placebo at 12 weeks (3 studies; SMD, 0.33; 95\% CI, 0.20-0.46; P<0.00001) $(3,24,25)$ and 24 weeks ( 3 studies; SMD, $0.23 ; 95 \%$ CI, 0.04-0.42; $\mathrm{P}=0.02$; Table III) $(3,24,27)$. Creatinine levels were significantly higher 
Table III. Safety and laboratory outcomes of baricitinib in patients with active rheumatoid arthritis.

A, Baricitinib, $4 \mathrm{mg}, 12$ weeks

\begin{tabular}{|c|c|c|c|c|c|c|c|}
\hline \multirow[b]{2}{*}{ Studies (n) } & \multirow[b]{2}{*}{ Outcome } & \multicolumn{3}{|c|}{ Meta-analysis } & \multicolumn{3}{|c|}{ Test of heterogeneity } \\
\hline & & RR & $95 \% \mathrm{CI}$ & P-value & Model & $\mathrm{P}$-value & $\mathrm{I}^{2}(\%)$ \\
\hline 4 & Discontinuation due to AEs & 1.15 & 0.60 to 2.22 & 0.67 & $\mathrm{~F}$ & 0.47 & 0 \\
\hline 3 & Serious infection & 0.83 & 0.26 to 2.71 & 0.76 & $\mathrm{~F}$ & 0.75 & 0 \\
\hline 3 & ALT & $0.33^{\mathrm{a}}$ & 0.20 to 0.46 & $<0.01$ & $\mathrm{~F}$ & 0.51 & 0 \\
\hline 3 & Neutrophils & $-0.64^{\mathrm{b}}$ & -0.87 to -0.41 & $<0.01$ & $\mathrm{~F}$ & 0.22 & 33 \\
\hline 3 & Lymphocytes & $0.07^{\mathrm{b}}$ & -0.08 to 0.21 & 0.35 & $\mathrm{R}$ & 0.05 & 66 \\
\hline 3 & Creatinine & $0.05^{\mathrm{b}}$ & 0.03 to 0.06 & $<0.01$ & $\mathrm{~F}$ & 0.49 & 0 \\
\hline 3 & HDL & $7.87^{\mathrm{b}}$ & 6.43 to 9.30 & $<0.01$ & $\mathrm{~F}$ & 0.73 & 0 \\
\hline
\end{tabular}

B, Baricitinib, $4 \mathrm{mg}, 24$ weeks

\begin{tabular}{|c|c|c|c|c|c|c|c|}
\hline \multirow[b]{2}{*}{ Studies (n) } & \multirow[b]{2}{*}{ Outcome } & \multicolumn{3}{|c|}{ Meta-analysis } & \multicolumn{3}{|c|}{ Test of heterogeneity } \\
\hline & & RR & $95 \% \mathrm{CI}$ & P-value & Model & P-value & $\mathrm{I}^{2}(\%)$ \\
\hline 3 & Discontinuation due to AEs & 1.38 & 0.90 to 2.13 & 0.14 & $\mathrm{~F}$ & 0.91 & 0 \\
\hline 3 & Serious infection & 0.94 & 0.47 to 1.88 & 0.86 & $\mathrm{~F}$ & 0.82 & 0 \\
\hline 3 & ALT & $0.23^{\mathrm{a}}$ & 0.04 to 0.42 & 0.02 & $\mathrm{R}$ & 0.02 & 73 \\
\hline 3 & Neutrophils & $-0.67^{b}$ & -0.87 to -0.47 & $<0.01$ & $\mathrm{~F}$ & 0.49 & 0 \\
\hline 3 & Lymphocytes & $-0.02^{\mathrm{b}}$ & -0.08 to 0.05 & 0.61 & $\mathrm{~F}$ & 0.30 & 17 \\
\hline 3 & Creatinine & $0.05^{\mathrm{b}}$ & 0.03 to 0.06 & $<0.01$ & $\mathrm{R}$ & 0.10 & 57 \\
\hline 3 & HDL & $8.69^{b}$ & 7.46 to 9.91 & $<0.01$ & $\mathrm{~F}$ & 0.26 & 26 \\
\hline
\end{tabular}

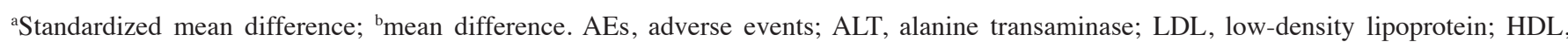
high-density lipoprotein; RR, relative risk; R, random-effects model; F, fixed-effects model; CI, confidence interval; $\mathrm{I}^{2}$, heterogeneity.

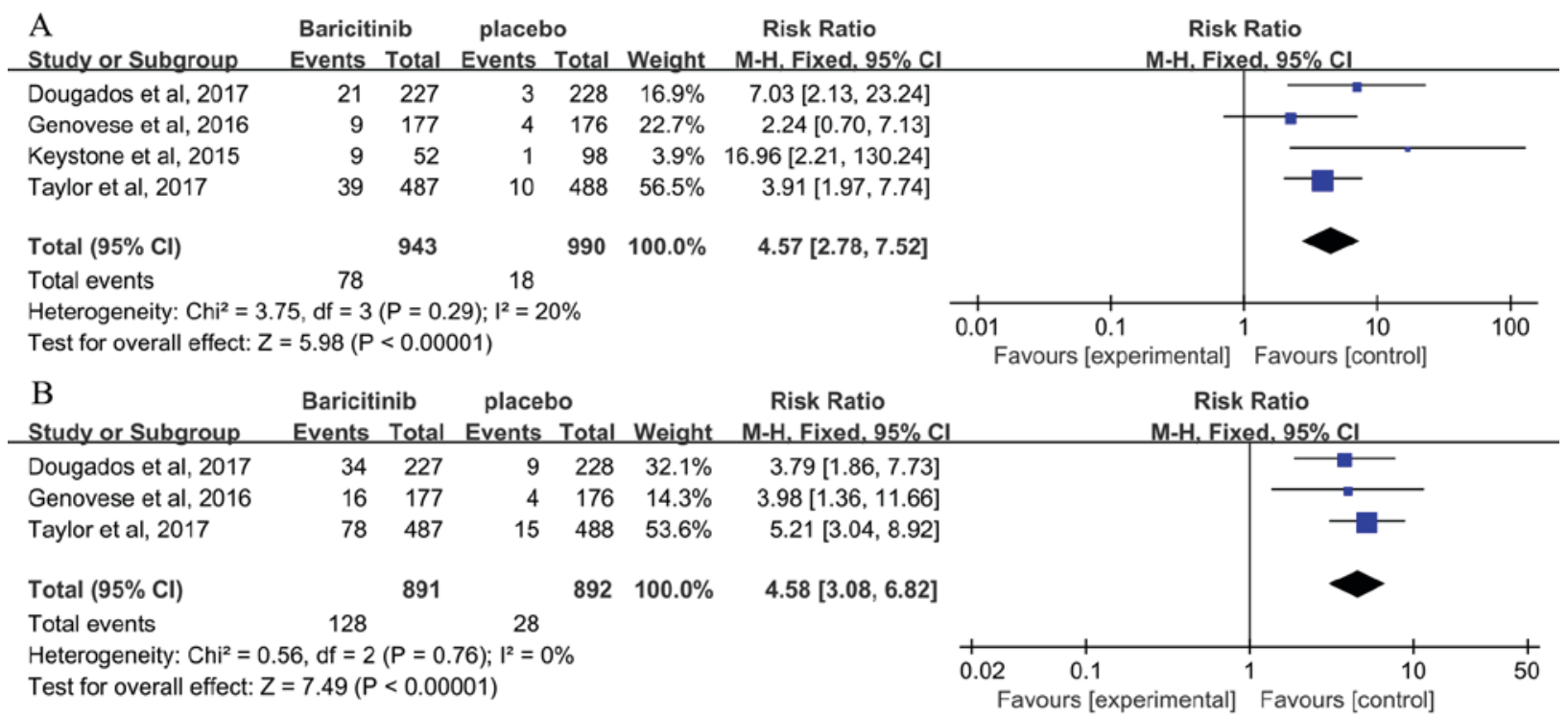

Figure 4. Forest plot diagram for the efficacy of baricitinib at dose of $4 \mathrm{mg}$ once daily according to a Simplified Disease Activity Index score of $\leq 3.3$ in patients with rheumatoid arthritis at (A) 12 weeks and (B) 24 weeks. CI, confidence interval; df, degrees of freedom; M-H, Mantel-Haentzel. Risk ratio is presented as blue squares, with the horizontal line indicating the confidence interval. Combined results for all studies are presented as a black diamonds.

in the baricitinib group compared with those in the placebo group at 12 weeks (3 studies; MD, 0.05; 95\% CI, 0.03-0.06;
$\mathrm{P}<0.00001)(3,24,25)$ and 24 weeks (3 studies; MD, 0.05; 95\% CI, 0.03-0.06; $\mathrm{P}<0.00001$; Table III) $(3,24,27)$. 


\begin{tabular}{|c|c|c|c|c|c|c|c|c|}
\hline $\begin{array}{l}\text { A } \\
\text { Study or Subgroup }\end{array}$ & \multicolumn{2}{|c|}{ Baricitinib } & \multicolumn{2}{|c|}{$\begin{array}{l}\text { placebo } \\
\text { Events Total }\end{array}$} & Weight & $\begin{array}{c}\text { Risk Ratio } \\
\text { M-H. Fixed. } 95 \% \mathrm{Cl}\end{array}$ & \multicolumn{2}{|c|}{$\begin{array}{c}\text { Risk Ratio } \\
\text { M-H. Fixed. } 95 \% \mathrm{Cl}\end{array}$} \\
\hline Dougados et al, 2017 & 135 & 227 & 133 & 228 & $8 \quad 47.9 \%$ & $1.02[0.87,1.19]$ & & \\
\hline Genovese et al, 2016 & 119 & 177 & 96 & 176 & $6 \quad 34.7 \%$ & $1.23[1.04,1.46]$ & & \\
\hline Keystone et al, 2015 & 22 & 52 & 45 & 98 & $3 \quad 11.3 \%$ & $0.92[0.63,1.35]$ & & \\
\hline Tanaka et al, 2018 & 13 & 24 & 26 & 49 & $6.2 \%$ & $1.02[0.65,1.61]$ & & \\
\hline \multicolumn{2}{|l|}{ Total $(95 \% \mathrm{Cl})$} & 480 & & 551 & $100.0 \%$ & $1.08[0.97,1.20]$ & & \\
\hline \multirow{2}{*}{\multicolumn{7}{|c|}{$\begin{array}{l}\text { Total events } \quad 289 \quad 300 \\
\text { Heterogeneity: } \text { Chi }^{2}=3.58, d f=3(P=0.31) ; I^{2}=16 \% \\
\text { Test for overall effect: } Z=1.46(P=0.14)\end{array}$}} & & \\
\hline & & & & & & & $\begin{array}{ccc}0.5 & 0.7 & 1 \\
\text { Favours [experimental] }\end{array}$ & \begin{tabular}{|ccc}
1 & 1.5 & 2 \\
& Favours [control]
\end{tabular} \\
\hline $\begin{array}{l}\text { B } \\
\text { Study or Subgroup }\end{array}$ & \multicolumn{2}{|c|}{$\begin{array}{l}\text { Baricitinib } \\
\text { Events Total }\end{array}$} & \multicolumn{2}{|c|}{$\begin{array}{l}\text { placebo } \\
\text { Events Total }\end{array}$} & Weight & $\begin{array}{l}\text { Risk Ratio } \\
\text { M-H. Random. } 95 \% \mathrm{Cl}\end{array}$ & $\begin{array}{r}\text { Risk } \\
\text { M-H. Rand }\end{array}$ & $\begin{array}{l}\text { Ratio } \\
\text { dom. } 95 \% \mathrm{Cl}\end{array}$ \\
\hline Dougados et al, 2017 & 162 & 227 & 161 & 228 & $32.7 \%$ & $1.01[0.90,1.14]$ & \\
\hline Genovese et al, 2016 & 137 & 177 & 112 & 176 & $28.7 \%$ & $1.22[1.06,1.40]$ & & $\rightarrow-$ \\
\hline Taylor et al, 2017 & 347 & 487 & 295 & 488 & $38.6 \%$ & $1.18[1.08,1.29]$ & & - \\
\hline Total $(95 \% \mathrm{Cl})$ & & 891 & & 892 & $100.0 \%$ & $1.13[1.01,1.26]$ & & \\
\hline Total events & 646 & & 568 & & & & & \\
\hline \multicolumn{7}{|c|}{$\begin{array}{l}\text { Heterogeneity: } \text { Tau }^{2}=0.01 ; \mathrm{Chi}^{2}=5.40, \mathrm{df}=2(P=0.07) ;\left.\right|^{2}=63 \% \\
\text { Test for overall effect: } Z=2.23(P=0.03)\end{array}$} & $\begin{array}{cc}1 & 1 \\
0.5 & 0.7 \\
\text { Favours [experimental] }\end{array}$ & $\begin{array}{ccc} & 1 & 1 \\
1 & 1.5 & 2 \\
& \text { Favours [control] }\end{array}$ \\
\hline
\end{tabular}

Figure 5. Forest plot diagram for the safety of baricitinib at dose of $4 \mathrm{mg}$ once daily according to the adverse events in patients with rheumatoid arthritis at (A) 12 weeks and (B) 24 weeks. CI, confidence interval; df, degrees of freedom; M-H, Mantel-Haentzel. Risk ratio is presented as blue squares, with the horizontal line indicating the confidence interval. Combined results for all studies are presented as a black diamonds.

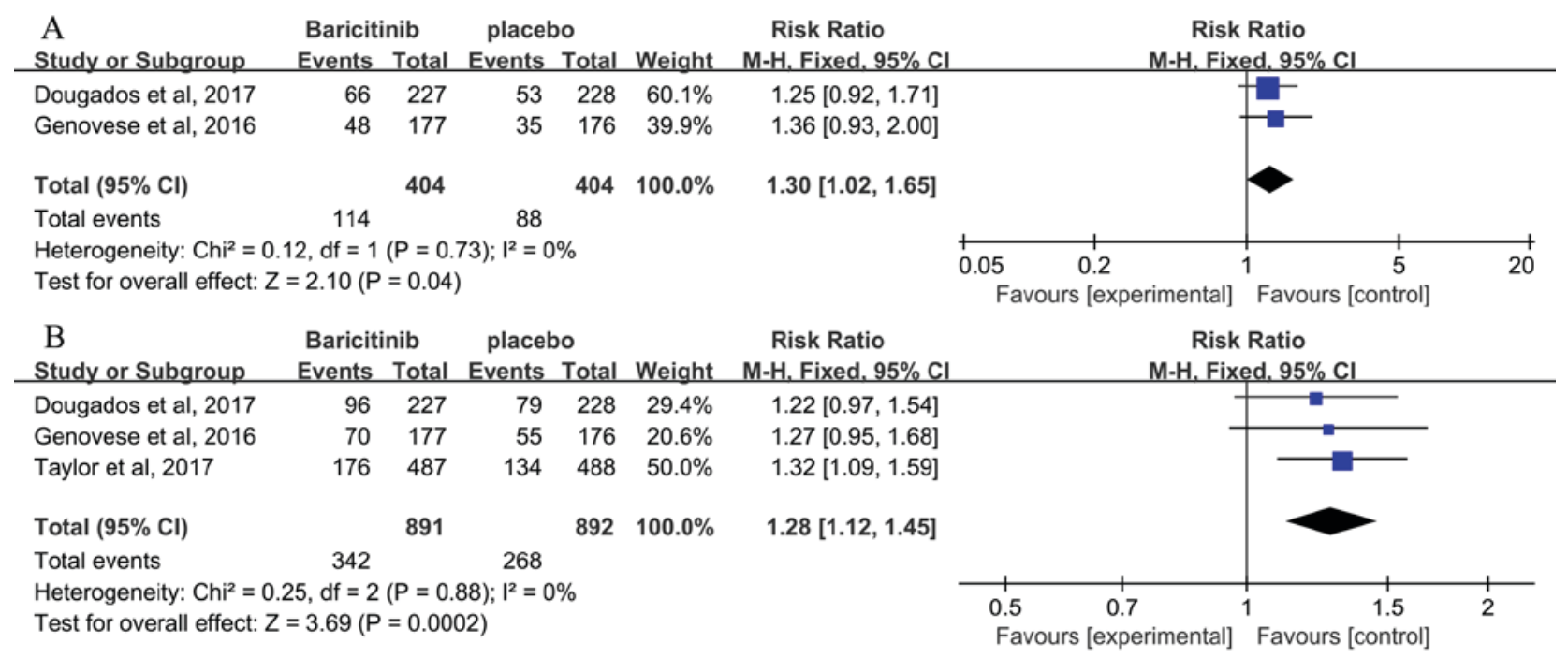

Figure 6. Forest plot diagram for the safety of baricitinib at dose of 4 mg once daily according to the occurrence of infection in patients with rheumatoid arthritis at (A) 12 weeks and (B) 24 weeks. CI, confidence interval; df, degrees of freedom; M-H, Mantel-Haentzel. Risk ratio is presented as blue squares, with the horizontal line indicating the confidence interval. Combined results for all studies are presented as a black diamonds.

LDL and HDL levels. Baricitinib was associated with significantly higher LDL levels than placebo at 12 weeks (3 studies; MD, 12.28; 95\% CI, 6.58-17.98; $\mathrm{P}<0.00001)(3,24,25)$ and 24 weeks ( 3 studies; MD, 16.26; 95\% CI, 8.63-23.89; $\mathrm{P}<0.00001$; Fig. 8$)(3,24,27)$. Similarity, patients receiving baricitinib had significantly higher HDL levels compared with those receiving placebo at 12 weeks (3 studies; MD, 7.87; 95\% CI, 6.43-9.30; $\mathrm{P}<0.00001)(3,24,25)$ and 24 weeks (3 studies; MD, 8.69; 95\% CI, 7.46-9.91; P<0.00001; Table III) $(3,24,27)$.

\section{Discussion}

In the present meta-analysis, clinical data of 2 phase-II and 5 phase-III trials using baricitinib at dose of $4 \mathrm{mg}$ once daily for a short term ( 24 weeks) were pooled. The studies indicated that $4 \mathrm{mg}$ baricitinib was the most effective dose. Baricitinib at a dose of 2 and $4 \mathrm{mg}$ provided significant clinical improvements compared with the placebo at 12 and 24 weeks. However, clinical benefits were larger in the $4 \mathrm{mg}$ baricitinib group compared with those in the $2 \mathrm{mg}$ baricitinib group. Baricitinib at a dose of 4 and $8 \mathrm{mg}$ had similar effective outcomes, but $8 \mathrm{mg}$ baricitinib was associated with a higher incidence rate of adverse events and abnormalities in laboratory parameters $(25,28)$.

The present meta-analysis focused on the treatment with baricitinib at $4 \mathrm{mg}$ once a day for 12 and 24 weeks. The ACR 20 response rate was the primary end-point to assess the efficacy of baricitinib (14). According to the present meta-analysis, the 


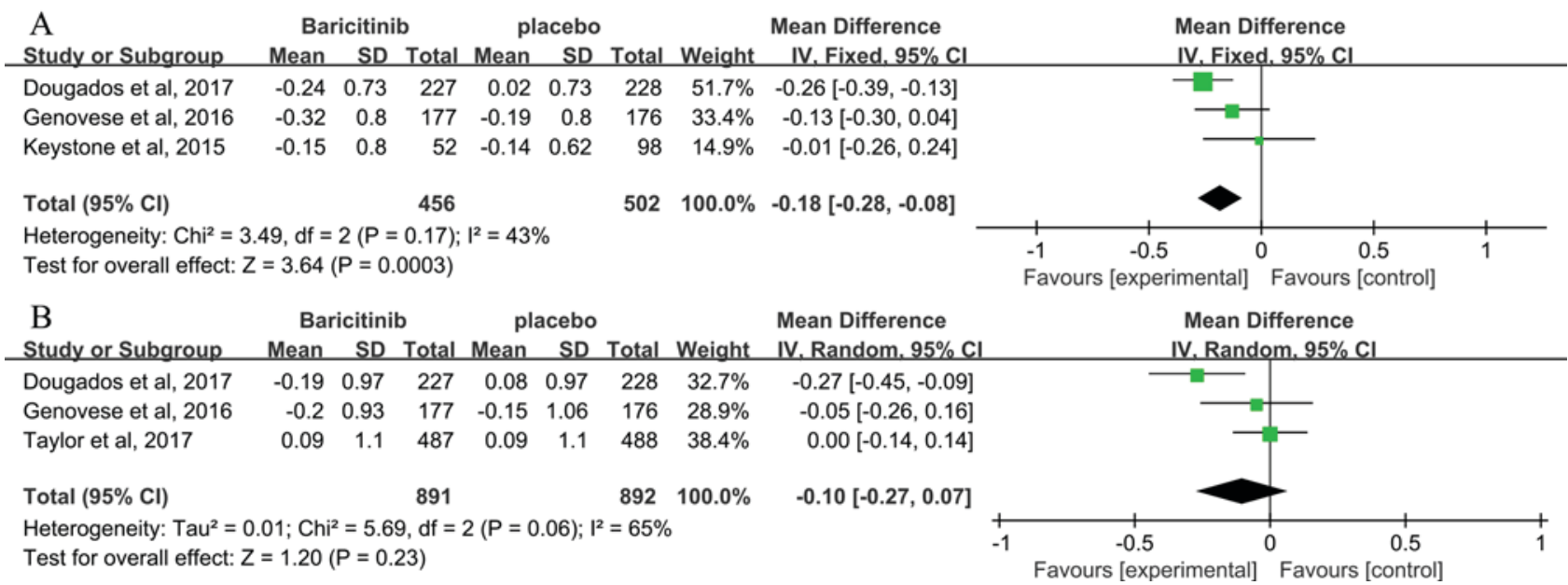

Figure 7. Forest plot diagram for the safety of baricitinib at the dose of $4 \mathrm{mg}$ once daily on the hemoglobin levels in patients with rheumatoid arthritis at (A) 12 weeks and (B) 24 weeks. CI, confidence interval; df, degrees of freedom; IV, inverse variance. Risk ratio is presented as green squares, with the horizontal line indicating the confidence interval. Combined results for all studies are presented as a black diamonds.

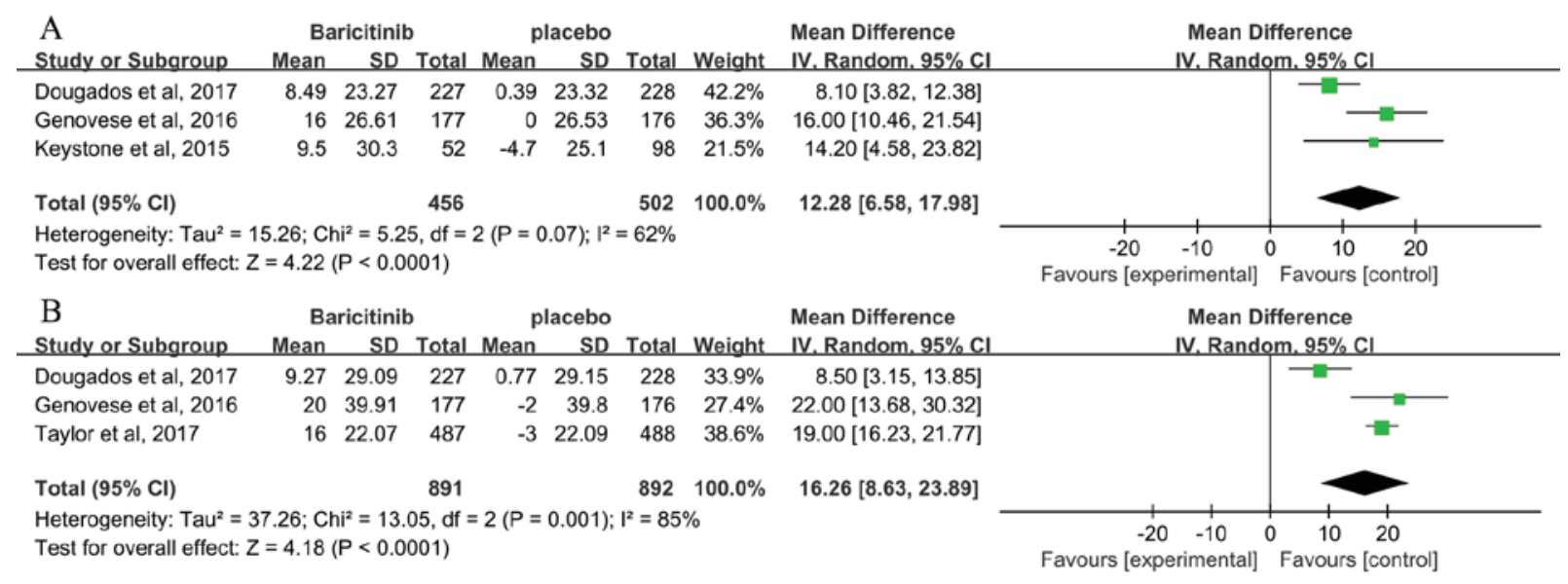

Figure 8. Forest plot diagram for the safety of baricitinib at the dose of $4 \mathrm{mg}$ once daily based on the low-density lipoprotein levels in patients with rheumatoid arthritis at (A) 12 weeks and (B) 24 weeks. CI, confidence interval; df, degrees of freedom; IV, inverse variance. Risk ratio is presented as green squares, with the horizontal line indicating the confidence interval. Combined results for all studies are presented as a black diamonds.

ACR20 response rate was significantly higher in the baricitinib group compared with that in the placebo group at 12 and 24 weeks, a significant clinical benefit of the administration of baricitinib (4 mg) was revealed. As effective measures, other PROs were also associated with a significant improvement in the baricitinib group compared with that in the placebo group at 12 and 24 weeks, and the improvement of PROs occurred rapidly and at a high magnitude $(3,24,26,29)$.

The baricitinib group had a significantly lower neutrophil count compared with that in the placebo group at 12 and 24 weeks. Clinical laboratory measures potentially allow for the evaluation of the safety of baricitinib, which inhibits the JAK/STAT pathway and finally changes the whole blood cell counts. JAK3 has a crucial role in the growth and maturation of lymphocytes, which may be induced by interleukin (IL) $-2,-4,-7,-9,-15$ and -21 (30). Compared with other JAKs, baricitinib has a relatively low inhibitory effect on JAK3, and thus, no significant difference was observed in the lymphocyte count between the baricitinib and placebo groups. The baricitinib group had a significantly lower neutrophil count compared with that in the placebo group, and the inhibition of cytokine-induced STAT3 phosphorylation may have been partly accountable for this. Hemoglobin was significantly reduced in the baricitinib group compared with that in the placebo groups at 12 weeks, but no significant difference was observed at 24 weeks. A decrease in hemoglobin may be due to the inhibition of JAK2 phosphorylation, which has an important role in signal transduction of erythropoietin $(4,31)$. Regarding other safety outcomes (ALT, creatinine, HDL and LDL), they were significantly higher in the baricitinib group compared with those in the placebo group over a short-term period (24 weeks). The mechanisms of these changes remain elusive, but the increase in creatinine may be caused by inhibition of tubular secretion. The increases in HDL and LDL with treatment of baricitinib were similar to those observed with other therapies that inhibit JAK and IL-6 activity $(4,32,33)$. However, most changes in laboratory parameters were minor and transient, and the clinical significance of these changes remains elusive $(3,24,27)$. Further studies with larger numbers of different populations and long-term exposure are required for safety evaluation. 
Baricitinib had a similar clinical efficacy, but nearly all of the laboratory outcomes were identified to be significantly changed. These changes were transient and generally within normal ranges. Only two eligible studies included in the present meta-analysis reported a statistically significant reduction in radiographic progression, which delayed joint damage in the baricitinib groups compared with that in the placebo groups in the short term (24 weeks) $(3,27)$. Similarly, radiographic progression exhibited a significant reduction in the baricitinib + MTX group compared with that in the MTX monotherapy group from 24 to 52 weeks (19). Long-term results on radiographic progression are required for evaluating the efficacy of baricitinib in reducing joint damage.

Several limitations of the present meta-analysis study should be considered: i) The reliability of the results of the present study is limited due to a lack of associated studies and the small sample of the included RCTs; ii) the follow-up was short, and thus, the long-term efficacy and safety of baricitinib were not determined; iii) radiographic progression is vital for assessing joint damage; however, this was not included in the present meta-analysis due to a lack of data; iv) the results on the ACR 20 and SDAI $\leq 3.3$ rates may have been influenced by partial data collection from published figures due to data extraction using 'Get Data Graph Digitizer' software.

In conclusion, the present meta-analysis demonstrated that selective inhibition of the JAK/STAT signaling pathway with baricitinib produced a clinical improvement in the treatment of RA within a short-term treatment period. Baricitinib (4 mg once daily) was the most effective dosage in patients with an inadequate response to conventional synthetic or biological DMARDs. Nearly all of the laboratory outcomes exhibited significant changes in the baricitinib group compared with the placebo group, but the clinical significance of these changes remains elusive. High-quality RCTs with long-term exposure and different populations are required to determine the efficacy and safety of baricitinib.

\section{Acknowledgements}

Not applicable.

\section{Funding}

The present study was supported by the Hospital Level Project of Subei People's Hospital (grant no. yzucms201623).

\section{Availability of data and materials}

The analyzed data sets generated during the study are available from the corresponding author on reasonable request.

\section{Authors' contributions}

ZPW and PZ performed the data selection. JZB and YL performed the data analysis. Sensitivity analyses were performed by JCW. Data disagreements were resolved by JSH. The final version of the manuscript has been read and approved by all authors, and each author believes that the manuscript represents honest work.

\section{Ethical approval and consent to participate}

This study was approved by the Ethics Committee of The Second Xiangya Hospital of Central South University (Changsha, China).

\section{Patient consent for publication}

Not applicable.

\section{Competing interests}

The authors declare that they have no competing interests.

\section{References}

1. Carr A, Hewlett S, Hughes R, Mitchell H, Ryan S, Carr M and Kirwan J: Rheumatology outcomes: The patient's perspective. J Rheumatol 30: 880-883, 2003.

2. Furst DE and Emer P: Rheumatoid arthritis pathophysiology: Update on emerging cytokine and cytokine-associated cell targets. Rheumatology 53: 1560-1569, 2014.

3. Dougados M, van der Heijde D, Chen YC, Greenwald M, Drescher E, Liu J, Beattie S, Witt S, de la Torre I, Gaich C, et al: Baricitinib in patients with inadequate response or intolerance to conventional synthetic DMARDs: Results from the RA-BUILD study. Ann Rheum Dis 76: 88-95, 2017.

4. Kubo S, Nakayamada S and Tanaka Y: Baricitinib for the treatment of rheumatoid arthritis. Expert Rev Clin Immunol 12: 911-919, 2016.

5. Iwata S and Tanaka Y: Progress in understanding the safety and efficacy of Janus kinase inhibitors for treatment of rheumatoid arthritis. Expert Rev Clin Immunol 12: 1047-1057, 2016.

6. Darnell JE Jr, Kerr IM and Stark GR: Jak-STAT pathways and transcriptional activation in response to IFNs and other extracellular signaling proteins. Science 264: 1415-1421, 1994.

7. Fridman JS, Scherle PA, Collins R, Burn TC, Li Y, Li J, Covington MB, Thomas B, Collier P, Favata MF, et al: Selective inhibition of JAK 1 and JAK2 is efficacious in rodent models of arthritis: Preclinical characterization of INCB028050. J Immunol 184: 5298-5307, 2010.

8. Shi JG, Chen X, Lee F, Emm T, Scherle PA, Lo Y, Punwani N, Williams WV and Yeleswaram S: The pharmacokinetics, pharmacodynamics, and safety of baricitinib, an oral JAK $1 / 2$ inhibitor, in healthy volunteers. J Clin Pharmacol 54: 1354-1361, 2014.

9. Kubo S, Nakayamada S, Nakano K and Tanaka Y: THU0203 baricitinib targets the type I IFN/STAT-medicated activities of human T cells and dendritic cells. Ann Rheum Dis 75 (Suppl 2): S260, 2016.

10. Emery P, Mcinnes I, Genovese MC, Smolen JS, Kremer J, Dougados M, Schlichting DE, Rooney T, Issa M, Bono Sd, et al: A7.16 Characterisation of changes in lymphocyte subsets in baricitinib-treated patients with rheumatoid arthritis in two phase 3 studies. Ann Rheum Dis 75 (Suppl 1): A62, 2016.

11. Song GG, Bae SC and Lee YH: Efficacy and safety of tofacitinib for active rheumatoid arthritis with an inadequate response to methotrexate or disease-modifying antirheumatic drugs: A meta-analysis of randomized controlled trials. Korean J Intern Med 29: 656-663, 2014.

12. Meyer DM, Jesson MI, Li X, Elrick MM, Funckes-Shippy CL, Warner JD, Gross CJ, Dowty ME, Ramaiah SK, Hirsch JL, et al: Anti-inflammatory activity and neutrophil reductions mediated by the JAK1/JAK 3 inhibitor, CP-690,550, in rat adjuvant-induced arthritis. J Inflamm (Lond) 7: 41, 2010.

13. Moher D, Liberati A, Tetzlaff J and Altman DG; PRISMA Group: Preferred reporting items for systematic reviews and meta-analyses: The PRISMA statement. PLoS Med 6: e1000097, 2009.

14. Felson DT, Anderson JJ, Boers M, Bombardier C, Furst D, Goldsmith C, Katz LM, Lightfoot R Jr, Paulus H, Strand V, et al: American College of Rheumatology. Preliminary definition of improvement in rheumatoid arthritis. Arthritis Rheum 38: 727-735, 1995. 
15. Aletaha D and Smolen J: The Simplified Disease Activity Index (SDAI) and the Clinical Disease Activity Index (CDAI): A review of their usefulness and validity in rheumatoid arthritis. Clin Exp Rheumatol 23 (5 Suppl 39): S100-S108, 2005.

16. van Tuyl LH and Boers M: Patient's global assessment of disease activity: What are we measuring? Arthritis Rheum 64: 2811-2813, 2012

17. Bruce B and Fries JF: The Health Assessment Questionnaire (HAQ). Clin Exp Rheumatol 23 (Suppl 39): S14-S18, 2005.

18. Higgins JP and Green S (eds): Cochrane handbook for systematic reviews of interventions version 5.1.0. Naunyn-Schmiedebergs Archiv Für Exp Pathol und Pharmakol 5: S38, 2011.

19. Fleischmann R, Schiff M, van der Heijde D, Ramos-Remus C, Spindler A, Stanislav M, Zerbini CA, Gurbuz S, Dickson C, de Bono S, et al: Baricitinib, methotrexate, or combination in patients with rheumatoid arthritis and no or limited prior disease-modifying antirheumatic drug treatment. Arthritis Rheumatol 69: 506-517, 2017.

20. Tanaka Y, Ishii T, Cai Z, Schlichting D, Rooney T and Macias W: Efficacy and safety of baricitinib in Japanese patients with active rheumatoid arthritis: A 52-week, randomized, single-blind, extension study. Mod Rheumatol 28: 20-29, 2018.

21. Takeuchi T, Genovese M, Xie L, Issa M, Pinto Correia AL, Rooney T, Emoto K and Smolen J: OP0228 baricitinib dose step-down following disease control in patients with rheumatoid arthritis. Ann Rheumat Dis: 75 (Suppl 2): 144.1-144, 2016.

22. Keystone EC, Genovese MC, Schlichting DE, de la Torre I, Beattie SD, Rooney TP and Taylor PC: Safety and efficacy of baricitinib through 128 weeks in an open-label, longterm extension study in patients with rheumatoid arthritis. J Rheumatol 45: 14-21, 2018.

23. Kremer JM, Genovese MC, Keystone E, Taylor PC, Zuckerman SH, Ruotolo G, Schlichting DE, Crotzer VL, Nantz E, Beattie SD and Macias WL: Effects of baricitinib on lipid, apolipoprotein, and lipoprotein particle profiles in a phase iib study of patients with active rheumatoid arthritis. Arthritis Rheumatol 69: 943-952, 2017.

24. Genovese MC, Kremer J, Zamani O, Ludivico C, Krogulec M, Xie L, Beattie SD, Koch AE, Cardillo TE, Rooney TP, et al: Baricitinib in patients with refractory rheumatoid arthritis. N Engl J Med 374: 1243-1252, 2016.

25. Keystone EC, Taylor PC, Drescher E, Schlichting DE, Beattie SD, Berclaz PY, Lee CH, Fidelus-Gort RK, Luchi ME, Rooney TP, et al: Safety and efficacy of baricitinib at 24 weeks in patients with rheumatoid arthritis who have had an inadequate response to methotrexate. Ann Rheum Dis 74: 333-340, 2015.
26. Emery P, Blanco R, Maldonado Cocco J, Chen YC, Gaich CL DeLozier AM, de Bono S, Liu J, Rooney T, Chang CH and Dougados M: Patient-reported outcomes from a phase III study of baricitinib in patients with conventional synthetic DMARD-refractory rheumatoid arthritis. RMD Open 3: e000410, 2017.

27. Taylor PC, Keystone EC, van der Heijde D, Weinblatt ME, Del Carmen Morales L, Reyes Gonzaga J, Yakushin S, Ishii T, Emoto K, Beattie S, et al: Baricitinib versus placebo or adalimumab in rheumatoid arthritis. N Engl J Med 376: 652-662, 2017.

28. Tanaka Y, Emoto K, Cai Z, Aoki T, Schlichting D, Rooney T and Macias W: Efficacy and safety of baricitinib in Japanese patients with active rheumatoid arthritis receiving background methotrexate therapy: A 12-week, double-blind, randomized placebo-controlled study. J Rheumatol 43: 504-511, 2016.

29. Smolen JS, Kremer JM, Gaich CL, DeLozier AM, Schlichting DE, Xie L, Stoykov I, Rooney T, Bird P, Sánchez Bursón JM, et al: Patient-reported outcomes from a randomised phase III study of baricitinib in patients with rheumatoid arthritis and an inadequate response to biological agents (RA-BEACON). Ann Rheum Dis 76: 694-700, 2017.

30. Leonard WJ and O'Shea JJ: Jaks and STATs: Biological implications. Annu Rev Immunol 16: 293-322, 1998.

31. Pelletier S, Gingras S, Funakoshi-Tago M, Howell S and Ihle JN: Two domains of the erythropoietin receptor are sufficient for Jak2 binding/activation and function. Mol Cell Biol 26: 8527-8538, 2006.

32. Kawashiri SY, Kawakami A, Yamasaki S, Imazato T, Iwamoto N, Fujikawa K, Aramaki T, Tamai M, Nakamura $\mathrm{H}$, Ida $\mathrm{H}$, et al: Effects of the anti-interleukin-6 receptor antibody, tocilizumab, on serum lipid levels in patients with rheumatoid arthritis. Rheumatol Int 31: 451-456, 2011.

33. Souto A, Salgado E, Maneiro JR, Mera A, Carmona L and Gómez-Reino JJ: Lipid profile changes in patients with chronic inflammatory arthritis treated with biologic agents and tofacitinib in randomized clinical trials: A systematic review and meta-analysis. Arthritis Rheumatol 67: 117-127, 2015.

This work is licensed under a Creative Commons Attribution-NonCommercial-NoDerivatives 4.0 International (CC BY-NC-ND 4.0) License. 